\title{
Tempo porta ECG: desafios da equipe multidisciplinar e a importância da melhoria continua
}

\author{
Autores: Carolina F.Vasco, Vitor Alves Loures,Priscila Pereira Duarte de Oliveira,Suellen da \\ Fonseca,Humberto Cunha Castro \\ Intituição: Rede D'OR São Luiz Anália Franco
}

\section{Introdução:}

As doenças cardiovasculares, incluindo o infarto agudo do miocárdio representam um importante problema de saúde pública no Brasil e no mundo, apresentando altas taxas de incidência e mortalidade, que neste grupo representa 183,3/100.000, encontrando-se entre as maiores do mundo. O resultado do eletrocardiograma (ECG) é a chave da estratégica terapêutica devendo ser realizado em menos de 10 minutos.

\section{Objetivo:}

Garantir a realização do ECG em até 10 minutos nos pacientes com queixa de dor torácica.

\section{Resultados:}

Atualização do protocolo de dor torácica, treinamento da equipe da administração, tracer do paciente cardiológico no pronto socorro, sala e colaborador da enfermagem dedicados para a realização de ECG.

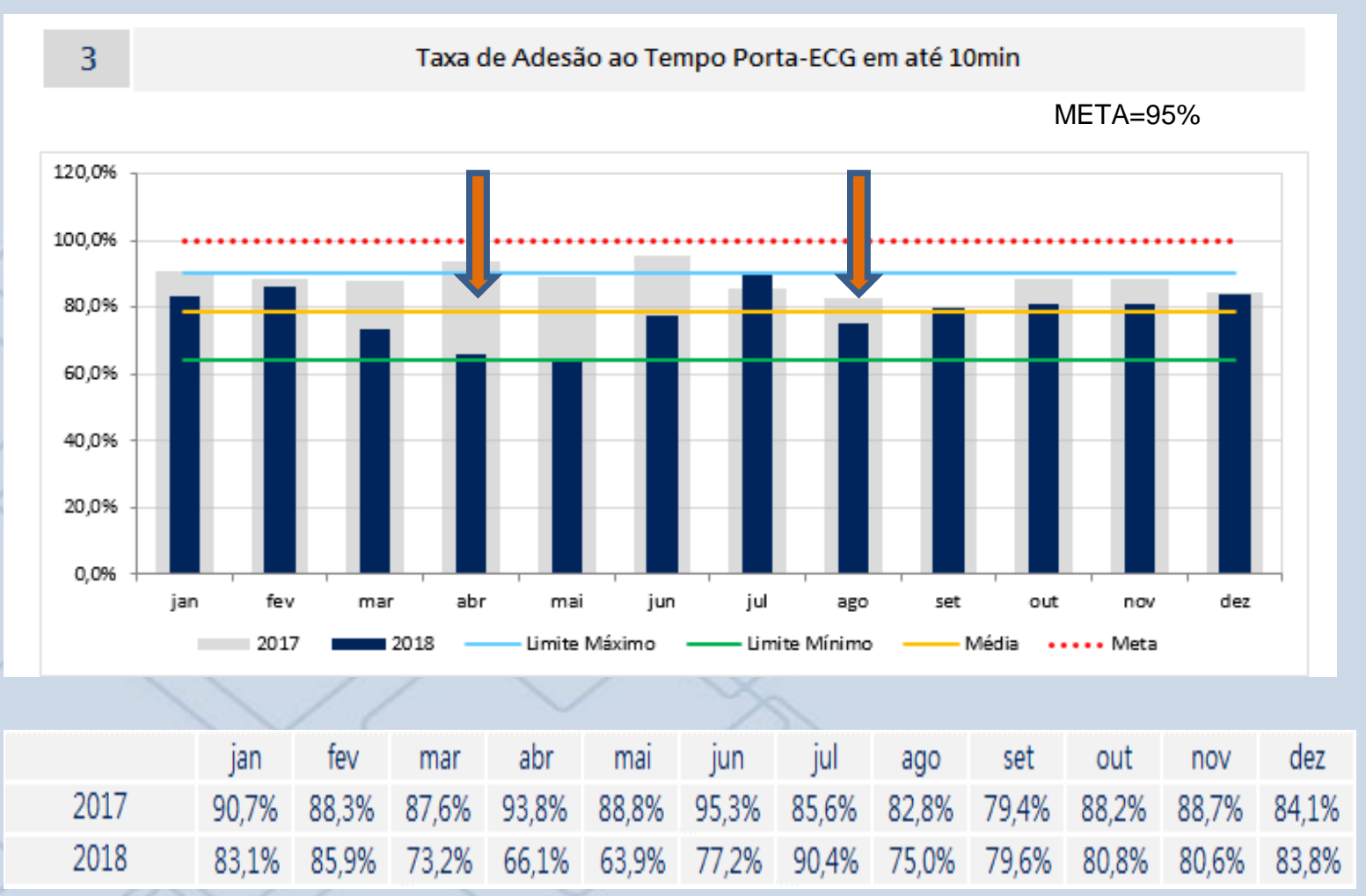

\section{Conclusão:}

Como a síndrome coronariana aguda representa quase $1 / 5$ das causas de dor torácica nas salas de emergência, e por possuir uma significativa morbimortalidade, a abordagem inicial desses pacientes é sempre feita no sentido de confirmar ou afastar este diagnóstico. Vários estudos têm sido realizados para determinar a acurácia diagnóstica e a utilidade da história clínica e do ECG em pacientes admitidos na sala de emergência com dor torácica para 0 diagnóstico de infarto agudo do miocárdio. O ECG exerce papel fundamental na avaliação de pacientes com dor torácica, tanto pelo seu baixo custo e ampla disponibilidade como pela relativa simplicidade de interpretação Desta forma, trabalhar a agilidade na realização do ECG na admissão dos pacientes com queixa de dor torácica na sala de emergência torna-se um desafio diário assim como o monitoramento do processo e implantação de melhorias contínuas.

\section{Referências Bibliográficas:}

1) Santos J, Meira KC, Camacho AR, Salvador PTCO, Guimarães RM, Pierin AMG, Simões TC, Freire FHMA. Mortalidade por infarto agudo do miocárdio no Brasil e suas regiões geográficas: análise do efeito da idadeperíodo-coorte. Ciência \& Saúde Coletiva, 23(5):1621-1634, 2018;

2) Bassan $R$, Pimenta $L$, Leães $P E$, Timerman A. I Diretriz de Dor Torácica na Sala de Emergência. Sociedade Brasileira de Cardiologia. Arq. Bras. Cardiol. vol.79 suppl.2 São Paulo Aug. 2002. 